\title{
Pitfalls in donor lung procurements: How should the procedure be taught to transplant trainees?
}

\author{
Norihisa Shigemura, MD, Jay Bhama, MD, Duc Nguyen, MD, Jnanesh Thacker, MD, \\ Christian Bermudez, MD, and Yoshiya Toyoda, MD
}

\begin{abstract}
Objective: The current trend in lung transplantation has led to liberalized lung donor selection criteria and use of marginal donors, with a corresponding requirement for improved procurement techniques to obtain high-quality donor grafts. Few reports, however, have provided recommendations for successful lung procurement procedures.
\end{abstract}

\begin{abstract}
Methods: We retrospectively studied 47 lung procurements performed by the University of Pittsburgh Medical Center team from January 2007 to December 2007. From those findings, we compared outcomes, as well as technical errors encountered, between procurements performed by trainees with limited transplant experience and by experienced transplant surgeons.

Results: Twenty-two of the procurements $(47 \%)$ were performed by experienced transplant surgeons and 25 $(53 \%)$ by supervised trainees. Patient characteristics and technical difficulties were comparable between the two groups. The trainees took more time to complete the procedure than did the experienced surgeons, although the difference was not significant. Furthermore, 21 of the cases performed by trainees $(84 \%)$ had one or more technical errors in the sequential steps of the procurement, including inadequate placement of the perfusion cannula in the main pulmonary artery $(60 \%)$, insufficient topical cooling $(56 \%)$, and inadequate timing of the start of pulmonary artery perfusion $(44 \%)$.

Conclusion: Donor lung procurements performed by beginners with limited transplant experience included frequent technical errors with regard to adequate graft preservation, which may lead to serious complications after transplant. Sequential steps in lung procurement techniques and better understanding of organ preservation should be an integral part of a lung transplant training program.
\end{abstract}

Lung transplantation has become an accepted therapeutic intervention for end-stage lung diseases ${ }^{1}$; however, it remains restricted as a viable therapeutic option by the limited supply of suitable donor lungs. ${ }^{2}$ To overcome this limitation, improvements in donor management and refinements in the techniques of donor lung procurement ${ }^{3,4}$ have led to aggressive liberalization of lung donor selection criteria by some institutions, ${ }^{5,6}$ with reported outcomes equivalent to those before liberalization and without adverse consequences for the patients. ${ }^{7,8}$ As a result, the techniques and technologies used for lung preservation during procurement have significantly improved during the past decade, and optimal perfusion flush delivery techniques with high-quality solutions and appropriate medications during the cold ischemic period have been refined through animal experimentation and applied clinically. ${ }^{9-11}$

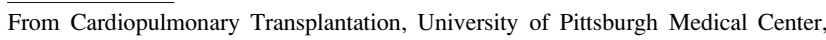
Pittsburgh, Pa.

Received for publication Jan 9, 2009; revisions received March 16, 2009; accepted for publication April 1, 2009.

Address for reprints: Norihisa Shigemura, MD, PhD, Department of General Thoracic Surgery, Osaka University Graduate School of Medicine, 2-2 (L5) Yamadaoka, Suita-City, Osaka, 565-0871 Japan (E-mail: shigemura@thoracic.med.osaka-u.ac. jp).

J Thorac Cardiovasc Surg 2009; 138:486-90

$0022-5223 / \$ 36.00$

Copyright (c) 2009 by The American Association for Thoracic Surgery doi:10.1016/j.jtcvs.2009.04.002
It has been emphasized that the use of marginal or extended donor lungs under the newly liberalized donor selection criteria requires optimal techniques for procurement, ${ }^{12}$ and without application of such techniques and knowledge throughout the procedure, imitation of the current trend alone may lead to poor transplant outcomes as a result of primary graft dysfunction (PGD). In addition, in most transplant centers in the United States, junior transplant trainees are often sent alone to donor hospitals for the procurement, mainly because of manpower issues. Unfortunately, it is difficult to find recommended procedures and potential pitfalls in donor lung procurement in literature for such trainees. ${ }^{13}$

In response to the increasing trend in liberalization of donor lung selection criteria in developed countries, we performed this study to examine the results of donor lung procurements performed by supervised trainees and compare them with the results of those performed by experienced transplant surgeons. Our aim in this study was to emphasize the importance of donor lung procurement in lung transplant, leading to a common recognition among the thoracic transplant community regarding how the procedures should be taught to trainees without compromising the quality of the donated organs.

\section{MATERIALS AND METHODS}

From January 2007 to December 2007, we performed primary lung transplants, exclusive of heart-lung transplant, in 123 patients for end-stage 


\section{Abbreviation and Acronym \\ $\mathrm{PGD}=$ primary graft dysfunction}

lung disease at the University of Pittsburgh Medical Center and participated in 120 donor lung procurements. Of the 120 procurements, those for which the procedure details were not recorded or another lung team was involved were excluded. All donor lung procurements were performed by trainees who had completed at least 3 years of cardiothoracic surgical training, and independent attending transplant surgeons supervised the trainees throughout the entire procedure process in all cases. There were six trainees assessed and four attending surgeons involved in this study.

\section{Sequential Steps in Donor Lung Procurement}

The sequential steps in our standard procurement procedure are summarized in Table 1. In our program, trainees (cardiothoracic transplant fellows) usually experience 5 to 10 cases under the supervision of a senior attending surgeon before they become independent. In addition to the use of proper technique in each sequential step, independent procurement surgeons, termed "recovery surgeons," are required to have excellent judgment in any sudden or emergency situation, as well as adequate communication skills with the recipient team and favorable cooperation with other organ teams encountered throughout the procedure.

\section{Assessment of Trainee by Supervisor}

During these procedures, each trainee was evaluated by the supervisor with regard to adequate performance without error of each sequential step shown in Table 1. The supervisors routinely asked the trainees what the next proper step was, and trainees were expected to respond immediately and accurately. If the response was inadequate, this was recorded and the trainee corrected by the supervisor before the step was actually performed. Thus all errors were recorded but did not result in any serious problems with the procurement.

In addition to the recording of errors, trainee performance was evaluated according to the following criteria: (1) time taken to complete the procedure (the time required from aortic crossclamping to departure from the donor hospital after packing the procured lung tissues and carrying them to the ambulance), (2) hemodynamic instability related to trainee performance, (3) major intraoperative trouble (such as bleeding from the great vessels or injury to the lungs), and (4) surgical damage to the grafts including the pulmonary vessels and inadequate atrial cuff.

\section{Data Analysis}

Statistical analysis was performed with the STAT-VIEW 5.0 software package (SAS Institute, Inc, Cary, NC). Continuous variables are expressed as mean $\pm \mathrm{SD}$. Comparisons between groups were done with the Student $t$ test, whereas categoric variables were analyzed with the Fisher exact test.

\section{RESULTS}

Forty-seven cases from January 2007 to December 2007 were analyzed in this study. Of those, 22 of the procurements $(47 \%)$ were performed by attending surgeons and $25(53 \%)$ were performed by supervised trainees. Donor demographic data and procedure details were comparable between the groups. No significant difference was observed with respect to the presence of intrathoracic adhesions, which are technically difficult to treat, encountered during the procedure. In addition, there were no significant differences between the
TABLE 1. Sequential steps used for donor lung procurement at University of Pittsburgh Medical Center

\begin{tabular}{cl}
\hline Step & \\
\hline 1 & Heparinization with 30,000 units of heparin intravenously \\
2 & Cannulation of $6.5 \mathrm{~F}$ curved metal-tipped cannula in proximal \\
& main pulmonary artery \\
3 & Azygos vein tied and divided and superior vena cava tied \\
4 & Prostaglandin $\mathrm{E}_{1}(500 \mu \mathrm{g})$ injected into main pulmonary \\
& artery in close proximity to cannula \\
5 & Inferior vena cava divided \\
6 & Aorta crossclamped \\
7 & Left atrial cut made to vent the pulmonary circulation \\
8 & Hypothermic pulmonary artery perfusion started with \\
9 & Perfadex (Vitrolife, Stockholm, Sweden) at 70 mL/kg \\
10 & Ice slush promptly put into chest cavity for topical cooling \\
& Frequent addition of ice slush into chest cavity to maintain \\
11 & topical cooling \\
& Periodic check on efflux of pneumoplegia from left atrial \\
12 & appendage \\
13 & Cardiectomy started once perfusion is complete \\
& Harvest of the lungs in a usual manner with lungs mildly \\
14 & inflated, avoiding overinflation \\
& Retrograde flush with 1 L Perfadex perfused for each lung at \\
& back table \\
\hline
\end{tabular}

groups with regard to the involvement of other organ teams (Table 2).

The trainees took more time to complete the procedure at the donor hospital (mean procurement time 60 minutes) than did the attending surgeons; however, the difference between the groups was not significant $(P=.68)$. One donor in the trainee group had a case with a large amount of bleeding from injury to the left innominate vein, leading to temporary hemodynamic instability. This situation was eventually corrected, and the procedure was completed by the attending surgeon with no major procedure-related trouble recorded. With respect to surgical damage to the grafts, a major inadequacy of the right main pulmonary artery in 1 case and that of a left atrial cuff in another case were noted in the trainees group, whereas no such technical errors were recorded in the procurements performed by the attending surgeons (Table 3 ). In both of cases of error, the inadequate portions of the grafts were properly reconstructed.

TABLE 2. Characteristics of donors and procurement procedures

\begin{tabular}{lccc}
\hline \multicolumn{1}{c}{ Characteristic } & $\begin{array}{c}\text { Attending } \\
\text { led }(\mathbf{n = 2 2})\end{array}$ & $\begin{array}{c}\text { Trainee led } \\
(\mathbf{n = 2 5})\end{array}$ & $\begin{array}{c}\boldsymbol{P} \\
\text { value }\end{array}$ \\
\hline Age (y, mean \pm SD) & $39 \pm 14.1$ & $36 \pm 9.8$ & .68 \\
Women & $53 \%$ & $48 \%$ & .42 \\
History of smoking & $41 \%$ & $69 \%$ & .26 \\
Chest wall adhesion & $32 \%$ & $44 \%$ & .45 \\
Previous cardiac surgery & $5 \%$ & $0 \%$ & .20 \\
Double-lung harvest & $91 \%$ & $96 \%$ & .65 \\
Heart team included & $82 \%$ & $84 \%$ & .58 \\
Abdominal team included & $95 \%$ & $96 \%$ & .71 \\
\hline
\end{tabular}


TABLE 3. Assessment of trainee performance during donor lung procurement as compared with performance by senior attending surgeons

\begin{tabular}{lccc}
\hline \multicolumn{1}{c}{ Characteristic } & $\begin{array}{c}\text { Attending led } \\
(\mathbf{n = 2 2})\end{array}$ & $\begin{array}{c}\text { Trainee led } \\
(\mathbf{n = 2 5 )}\end{array}$ & $\begin{array}{c}\boldsymbol{P} \\
\text { value }\end{array}$ \\
\hline $\begin{array}{l}\text { In-hospital time* (min, } \\
\quad \text { mean } \pm \text { SD) }\end{array}$ & $55 \pm 5.7$ & $60 \pm 8.8$ & .68 \\
Hemodynamic instability (\%) & 9 & & \\
Major intraoperative trouble (\%) & 0 & 12 & .45 \\
Surgical damage to grafts $(\%)$ & 0 & 4 & .25 \\
\hline
\end{tabular}

*From aortic crossclamping to departure from donor hospital.

The rates and types of errors made by the trainees during the procurement procedure are shown in Table 4 . Of the 25 procurements performed by the trainees, 21 had one or more errors made in the sequential steps of donor lung procurement, for an overall incidence of $84 \%$. The types of errors and their frequencies were as follows: 15 cases $(60 \%)$ of inadequate position of the cannula for hypothermic pulmonary artery perfusion, 14 cases $(56 \%)$ of inadequate topical cooling with ice slush placed into the thoracic cavity, 11 cases $(44 \%)$ of inadequate timing to start pulmonary perfusion after aortic crossclamping without confirmation of drainage from the heart, and 5 cases $(20 \%)$ in which the trainee forgot to flush prostaglandin into the pulmonary artery before performing aortic crossclamping.

In Table 5, data regarding the types and distribution of errors during procurement by individual trainees are shown. We found that the trainees tended to make more critical errors in their initial 2 or 3 cases and fewer after these experiences. From these data, we saw nothing to suggest that a single trainee could have been responsible for many of the errors in such a way as to have affected the statistical analysis.

The proper position for cannula placement to perform antegrade pulmonary artery perfusion, as taught to the trainees, is explained in Figure 1. Basically, we emphasize that cannulation should be performed proximal to the main pulmonary artery and as close as possible to the pulmonary valve while taking care to avoid damaging the valve, so as to secure an equivalent (even) and excellent perfusion of the bilateral lungs. We have found, however, that trainees tend to place the cannula too close to the bifurcation, leading to inferior quality for preservation as a result of the anatomic disadvantage of the right side, as shown in Figure 1.

TABLE 4. Types and incidences of errors encountered during

procurement by trainees $(n=25)$

\begin{tabular}{lcc}
\hline \multicolumn{1}{c}{ Error } & No. & $\%$ \\
\hline $\begin{array}{l}\text { Inadequate positioning of cannula for } \\
\quad \text { hypothermic pulmonary arterial }\end{array}$ & 15 & $60 \%$ \\
Insufficient topical cooling with ice slush & 14 & $56 \%$ \\
Inadequate timing of start of perfusion & 11 & $44 \%$ \\
Forgetting to flush prostaglandin $\mathrm{E}_{1}$ & 5 & $20 \%$ \\
\hline
\end{tabular}

TABLE 5. Distribution of types of errors during procurement by individual trainees

\begin{tabular}{lcccccc}
\hline & & \multicolumn{5}{c}{ Error types } \\
\cline { 2 - 7 } & & $\begin{array}{c}\text { Pulmonary } \\
\text { arterial } \\
\text { Trainee }\end{array}$ & Cases & Topical & Timing of \\
cannula & cooling & perfusion & PG flush & Other \\
\hline 1 & 6 & 3 & 2 & 2 & 1 & 1 \\
2 & 5 & 3 & 3 & 2 & 1 & 0 \\
3 & 5 & 2 & 3 & 2 & 2 & 1 \\
4 & 4 & 3 & 2 & 1 & 0 & 1 \\
5 & 3 & 2 & 2 & 2 & 1 & 0 \\
6 & 2 & 2 & 2 & 2 & 0 & 1 \\
Total & 25 & 15 & 14 & 11 & 5 & 4 \\
\hline
\end{tabular}

$P G$, Prostaglandin.

\section{DISCUSSION}

The results of this retrospective study indicate that donor lung procurement performed by a trainee with limited transplant experience may have frequent technical errors that are not acceptable in terms of excellent lung preservation. Previous studies ${ }^{14-16}$ have demonstrated the mechanisms and associated factors in occurrence of PGD, which is the end point of a series of donor lung injuries. From those findings, sequential steps in the procurement techniques used, such as composition of solutions used ${ }^{17}$ and the method for perfusion flushing, ${ }^{18,19}$ were devised to prevent injuries. Adequate completion of the procurement by following the steps is crucial in obtaining an excellent graft without injury. Although donor lung procurement is not technically

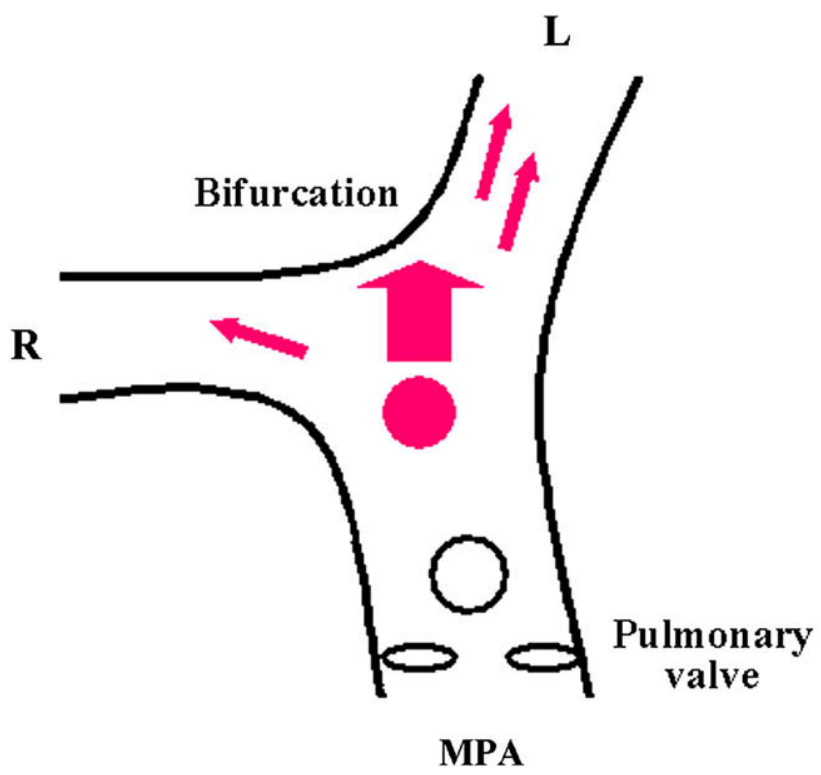

FIGURE 1. During procedure, cannula with curved tip is used for antegrade hypothermic pulmonary artery perfusion and placed proximally (open circle) on main pulmonary artery (MPA). When inadequately placed close to bifurcation (solid circle), perfusion may result in an uneven distribution (solid arrows), leading to inadequate preservation during cold ischemic time, especially with right graft. $L$, Left; $R$, right. 
demanding, it requires surgeons not only to use adequate cardiothoracic surgical techniques but also to understand proper organ preservation techniques. Thus the process should not be regarded as merely a surgical or technical issue related to pneumonectomy.

With respect to the errors noted in this study, the fact that errors related to inadequate perfusion techniques were prevalent demands our attention. Before our trainees begin to learn the procurement procedures, we emphasize that they should pay maximal attention to an even distribution of the perfused preservation solution, because poor distribution may damage the graft irreversibly, leading to an unfavorable short- or long-term transplant outcome. ${ }^{20,21}$ When the cannula is inadequately positioned close to the bifurcation, there are two solutions available: (1) change the direction of the curved cannula tip manually toward the right and left every few minutes, to make the distribution even, or (2) use a retrograde perfusion method in which the cannula tip is intentionally placed toward the pulmonary valves. Our experience has shown that trainees tend to focus more on starting the perfusion as quickly as possible because of time restrictions related to aortic crossclamping time and thus pay less attention to better preservation techniques while the solutions are perfusing the lungs, such as optimizing distribution or maintaining topical cooling by adding fresh ice slush into the thoracic cavity.

Despite concerns regarding the safety and efficacy of lung transplant with marginal donor lungs procured under liberalized donor lung selection criteria, such as from patients 60 years old or older, ${ }^{22}$ patients with longer smoking history, ${ }^{23}$ and patients with possible infection, ${ }^{24}$ excellent outcomes have been demonstrated to date. Additional evidence should be accumulated for a better understanding of the long-term quality issues; however, we believe that the current trend toward liberalization of donor selection criteria will prevail and become widely accepted in the thoracic transplant community. On the other hand, when marginal donor lungs are used, it is important for procurement surgeons to use sound techniques to obtain excellent lung preservation. If transplant surgeons do not have confidence in the quality of the procurement procedures used, such marginal lungs should not be used.

A limitation of our retrospective study is that it was impossible to determine the exact degree of intervention by an individual supervisor involved. Intervention may have varied greatly among the supervisors, leading to biased results. In addition, there was no means available to evaluate the outcome of trainee performance other than checking and counting the errors made during each sequential step of procurement. The lack of an independent observer involved in the study to check that the sequential steps performed by the attending surgeons were correct further limits the accuracy of the assessment in this study, although the attending surgeons were all experienced independent procurement surgeons with excellent records of quite a few procurements performed successfully.

It is evident that poor lung preservation caused by technical errors during the procedure are likely to contribute to serious postoperative complications after transplant, such as PGD. Actually, concerning the occurrence of PGD, there was not significant difference in study between the trainee and attending surgeon groups at 72 hours posttransplant (data not shown) in the grading of PGD severity, which is defined by International Society for Heart and Lung Transplantation. ${ }^{14-16}$ We believe that this is partly because the comparison study may be underpowered to allow outcome evaluations at this stage, and the impacting variables on the outcome in lung transplant surgery and medicine, including the characteristics of the donor and recipient as well as the transplant procedure, are nearly unlimited. ${ }^{14-16,25}$ It is therefore difficult to show how a single error during procurement can lead to an unfavorable result in the postoperative course or transplant outcome.

Although we believe that our protocol is a nice example of how to teach a procurement procedure to a trainee, we consider that trainees should also be taught that protocols may differ among institutions and that not all steps in a procedure are based on evidence from strict clinical trials. What is perceived to be a mistake by one team may well be routine practice on another team. Nevertheless, it is important to emphasize that maximal attention should be paid throughout the process of donor lung procurement to the achievement of an excellent graft through proper lung preservation procedures. We consider that no error in this procedure should be made, and this should be the first, critical step in pursuit of the long-term benefit for the patient.

In conclusion, we found that donor lung procurement procedures performed by beginners with limited transplant experience frequently included technical errors with regard to graft preservation, which may have an effect on transplant outcome. Although it was difficult to show how a technical error in each sequential step of procurement affected the quality of the graft, we consider it important to continue to pursue our policy of zero mistakes during the procurement procedure to prevent $\mathrm{PGD}$, leading to a successful transplant outcome with excellent graft preservation.

\section{References}

1. Hertz MI, Aurora P, Christie JD, Dobbels F, Edwards LB, Kirk R, et al. Registry of the International Society for Heart and Lung Transplantation: a quarter century of thoracic transplantation. J Heart Lung Transplant. 2008;27:937-42.

2. Pomfret EA, Sung RS, Allan J, Kinkhabwala M, Melancon JK, Roberts JP. Solving the organ shortage crisis: the 7th annual American Society of Transplant Surgeons' state-of-the-art winter symposium. Am J Transplant. 2008;8:745-52.

3. de Perrot M, Weder W, Patterson GA, Keshavjee S. Strategies to increase limited donor resources. Eur Respir J. 2004;23:477-82.

4. Botha P, Rostron AJ, Fisher AJ, Dark JH. Current strategies in donor selection and management. Semin Thorac Cardiovasc Surg. 2008;20:143-51.

5. Oto T, Griffiths A, Levvey B, Whitford H, Kotsimbos TC, Rabinov M, et al. Donor history of asthma is not a contraindication to lung transplantation: 12-year single-center experience. J Heart Lung Transplant. 2004;23:309-16. 
6. Toyoda Y, McCurry KR. Prior cardiac surgery is not a contraindication for lung donor. Ann Thorac Surg. 2007;84:314-6.

7. Sundaresan S, Semenkovich J, Ochoa L, Richardson G, Trulock EP, Cooper JD, et al. Successful outcome of lung transplantation is not compromised by the use of marginal lung donors. J Thorac Cardiovasc Surg. 1995;109:1075-80.

8. Bhorade SM, Vigneswaran W, McCabe MA, Garrity ER. Liberalization of donor criteria may expand the donor pool without adverse consequence in lung transplantation. J Heart Lung Transplant. 2000;19:1199-204.

9. Wittwer T, Fehrenbach A, Meyer D, Brandes H, Albes J, Richter J, et al. Retrograde flush perfusion with low-potassium solutions for improvement of experimental pulmonary preservation. J Heart Lung Transplant. 2000;19: 976-83.

10. Struber M, Wilhelmi M, Harringer W, Niedermeyer J, Anssar M, Kunsebeck A et al. Flush perfusion with low potassium dextran solution improves early graft function in clinical lung transplantation. Eur J Cardiothorac Surg. 2001;19: 190-4.

11. Aziz TM, Pillay TM, Corris PA, Forty J, Hilton CJ, Hasan A, et al. Perfadex for clinical lung procurement: is it an advance? Ann Thorac Surg. 2003;75:1960-4.

12. Pierre AF, Sekine Y, Hutcheon MA, Waddell TK, Keshavjee SH. Marginal donor lungs: a reassessment. J Thorac Cardiovasc Surg. 2002;123:421-8.

13. Sundaresan S, Trachiotis GD, Aoe M, Patterson GA, Cooper JD. Donor lung procurement: assessment and operative technique. Ann Thorac Surg. 1993;56: 1409-13.

14. de Perrot M, Bonser RS, Dark J, Kelly RF, McGiffin D, Menza R, et al. Report of the ISHLT working group on primary lung graft dysfunction part III: donorrelated risk factors and markers. J Heart Lung Transplant. 2005;24:1460-7.

15. Barr ML, Kawut SM, Whelan TP, Girgis R, Bottcher H, Sonett J, et al. Report of the ISHLT working group on primary lung graft dysfunction part IV: recipient-related risk factors and markers. J Heart Lung Transplant. 2005;24: 1468-82.
16. Arcasoy SM, Fisher A, Hachem RR, Scavuzzo M, Ware LB. Report of the ISHLT working group on primary lung graft dysfunction part $\mathrm{V}$ : predictors and outcomes. J Heart Lung Transplant. 2005;24:1483-8.

17. Thabut G, Vinatier I, Brugiere O, Leseche G, Loirat P, Bisson A, et al. Influence of preservation solution on early graft failure in clinical lung transplantation. Am J Respir Crit Care Med. 2001;164:1204-8.

18. Varela A, Cordoba M, Serrano-Fiz S, Burgos R, Montero CG, et al. Early lung allograft function after retrograde and antegrade preservation. $J$ Thorac Cardiovasc Surg. 1997;114:1119-20.

19. Pierre AF, DeCampos KN, Liu M, Edwards V, Cutz E, Slutsky AS, et al. Rapid reperfusion causes stress failure in ischemic rat lungs. J Thorac Cardiovasc Surg. 1998;116:932-42.

20. Baretti R, Bitu-Moreno J, Beyersdorf F, Matheis G, Francischetti I, Kreitmayr B. Distribution of lung preservation solutions in parenchyma and airways: influence of atelectasis and route of delivery. J Heart Lung Transplant. 1995;14:80-91.

21. Varela A, Montero CG, Cordoba M, Antequera A, Perez M, Tabuenca MJ, et al. Improved distribution of pulmonary flush solution to the tracheobronchial wall in pulmonary transplantation. Eur Surg Res. 1997;29:1-4.

22. de Perrot M, Waddell TK, Shargall Y, Pierre AF, Fadel E, Uy K, et al. Impact of donors aged 60 years or more on outcome after lung transplantation: results of an 11-year single-center experience. J Thorac Cardiovasc Surg. 2007;133:525-31.

23. Aigner C, Winkler G, Jaksch P, Seebacher G, Lang G, Taghavi S, et al. Extended donor criteria for lung transplantation-a clinical reality. Eur J Cardiothorac Surg. 2005;27:757-61.

24. Lardinois D, Banysch M, Korom S, Hillinger S, Rousson V, Boehler A, et al. Extended donor lungs: eleven years experience in a consecutive series. Eur J Cardiothorac Surg. 2005;27:762-7.

25. Whitson BA, Nath DS, Johnson AC, Walker AR, Prekker ME, Radosevich DM, et al. Risk factors for primary graft dysfunction after lung transplantation. $J$ Thorac Cardiovasc Surg. 2006;131:73-80. 